\title{
Union Catalogs in the Argentine Republic
}

$\mathrm{I}^{\mathrm{N}}$

$\mathrm{N}$ a recent College and Research Libraries article $^{1}$ the union catalog movement in Latin America was reviewed. That report supplied information useful for the investigation of such activities and revealed something of the progress attained in this field of librarianship.

The achievements of the Argentine Republic in the development of union catalogs, however, have never been recorded adequately. At the suggestion of the author of the article referred to above, the present writer agreed to prepare a more complete statement than any which has heretofore appeared in print.

Union catalog enterprises in the Argentine, though not extensive, give much promise of future accomplishment. They can be divided into three important groups, each with quite different characteristics: union author catalogs, centralized systematic catalogs, and union catalogs of periodical publications. A discussion of each type follows.

\section{Union Author Catalogs}

It is toward this aspect of collaboration among libraries that the most effective efforts have been directed, though the type is of less technical complexity than other varieties of union catalogs. An example is the union catalog of the Institute Bibliotechologico of the University of Buenos Aires, where the writer was superintendent

1 Downs, Robert B. "Latin American Union Catalogs." College and Research Libraries 7:210-13, July 1946. of the union catalog and photo-duplication laboratory until November I946. The history of this catalog, financed by the Rockefeller Foundation, is well-known to many librarians in the United States. Since the various schools which make up the University of Buenos Aires have their own libraries, with independent directors and administrative departments, the union catalog's objective is to compile a complete record of the university's library resources. Accordingly, the catalog includes the holdings of the following libraries:

Facultad de Ciencias Exactas

Facultad de Agronomía y Veterinaria

Facultad de Medicina

Facultad de Derecho y Ciencias Sociales

Facultad de Filosofía y Letras

Facultad de Ciencias Económicas.

In addition to representing the books in the six important libraries named, the cata$\log$ also records works housed in institutions and schools belonging to these faculties, as, for example, the Museo Etnográfico, Colegio Nacional de Buenos Aires, and the Instituto de Literatura Argentina. As the task of compiling the catalog continues, libraries of the remaining institutions, schools, laboratories, and other organizations will be covered.

Thus far, the union catalog has been limited to main author entry cards. The number of volumes represented is approximately 450,000 .

As for the technique of compilation, the work was divided by necessity into two stages. At first, microphotography was em- 
ployed to reproduce the cards. Later, because of the film shortage, cards had to be transcribed directly from the catalogs of the individual libraries. The system of cataloging used in the Vatican Library was adopted, in order to standardize procedures and to eliminate the diversity of forms found in the separate libraries. For filing cards, A.L.A. rules were followed. The library to which a particular book belonged was indicated by symbols, in accordance with the plan developed by McMurtrie, i.e., a first letter designated the name of the town or city and other letters stood for the name of the library.

\section{Centralized Systematic Catalogs}

In the Argentine Republic there exists a centralized systematic catalog, the structure and method of compilation of which are worthy of attention. The catalog is an agency of the library section of the Navy, a central organization for the library activities of this ministry. All the naval libraries are directed by the library section, where books are selected, cataloged, classified, prepared for lending, and distributed among the different libraries. Entries for the union catalog are prepared simultaneously. Therefore, even though the libraries are scattered throughout the zones controlled by the Navy, readers can learn from the central records the location of particular titles and the number of books possessed by any one of the libraries.

The library section has compiled six centralized catalogs, composed of about 90,000 cards each. Each unit comprises an author index (Vatican Library), a title index, and a systematic subject index (Universal Decimal Classification). Books are arranged on the shelves according to subjects, and each catalog card bears a call number. The destination of a book is shown on the back of the title card.
Any book acquired for the Navy is represented in the six centralized catalogs, regardless of the library in which it may be placed. Apart from these larger catalogs, the library section has edited others belonging to small libraries. Thus, each of the libraries has a catalog of the works forming its own collection. In order to be able to control the auxiliary libraries, the section keeps partial shelflists, helpful in verification processes. The whole enterprise is one of considerable technical complexity, demanding careful planning and close attention to detail, in order to provide effective service.

\section{Union Catalogs of Periodicals}

In 1940 there was prepared and published by the Argentine Committee of $\mathrm{Li}$ braries of Scientific and Technical Institutions a union catalog of periodical publications. The record is limited to periodicals of a scientific and technical character, excluding those in the humanities and other fields. Some 7387 titles are listed. Each entry indicates the location of files of the publication, using a system of Arabic numerals.

One disadvantage of the union catalog of periodical publications is the lack of a subject classification. Only the titles and holding libraries are shown. Nevertheless, the catalog is a valuable guide for research workers and librarians. Entries are arranged in alphabetical order, following the plan of the World List of Scientific Periodicals.

At the present moment the committee is engaged in the preparation of a supplement covering nearly the same number of titles included in the original printed catalog.

Another work in this field, on which the ink is hardly yet dry, is a catalog of periodical publications edited by the Library of the Unión Industrial Argentina, listing titles

(Continued on page 442) 